\title{
Vagal function in relation to gastro-oesophageal reflux and associated motility changes
}

\author{
RICHARD V HEATLEY, R J COLLINS, P D JAMES, MICHAEL ATKINSON
}

\section{Summary and conclusions}

Vagal function in 28 patients with gastro-oesophageal reflux was examined by determining gastric secretory response to insulin-induced hypoglycaemia and pulserate variation with respiration. Gastric secretory studies were also performed on 13 patients with duodenal ulcer who had not undergone operations. In all patients the presence and degree of oesophagitis were determined endoscopically and mucosal biopsy and oesophageal manometry were performed.

Seven of the 28 patients with gastro-oesophageal reflux showed evidence of impaired vagal efferent function in the upper alimentary tract. No such impairment was found in those patients who showed manometric evidence of oesophageal spasm secondary to gastro-oesophageal reflux. Low pulse-rate variation with respiration was found in 12 of 27 patients with gastro-oesophageal reflux, suggesting dysfunction of cardiac vagal fibres.

Impairment of efferent vagal supply may be a causative factor in some patients with gastro-oesophageal reflux but does not seem to be important in oesophageal spasm secondary to gastro-oesophageal reflux.

\section{Introduction}

Although loss of tone of the lower oesophageal sphincter is generally regarded as important in the pathogenesis of gastrooesophageal reflux, its cause is unknown. Several of the physiological abnormalities accompanying gastro-oesophageal reflux are similar to those after surgical truncal vagotomy, which predisposes to gastro-oesophageal reflux. The rise in lower oesophageal sphincter pressure in response to increased abdominal pressure is diminished in patients with gastro-oesophageal reflux $^{1}$ and also after surgical vagotomy. ${ }^{2}$ Gastric stasis occurs after truncal vagotomy, ${ }^{3}$ and gastric emptying may be delayed in patients with hiatal hernia. ${ }^{4}$ Furthermore, vagal impairment caused by diabetic autonomic neuropathy is associated with decreased lower oesophageal sphincter pressure and sometimes with gastro-oesophageal reflux.

We have investigated vagal function in patients with gastrooesophageal reflux using the gastric secretory response to insulininduced hypoglycaemia and the variation in heart rate with respiration.

\section{Patients and methods}

Thirty-four patients ( 20 men, 14 women) were admitted to the study after giving their informed consent. Their ages ranged from 31 to 76 years (mean 53), and none was diabetic. Radiological examination showed hiatal hernia in 32 patients. All patients gave a history of retrosternal burning discomfort and had demonstrable free gastrooesophageal reflux at barium meal examination. For comparative

General and University Hospitals, Nottingham

RICHARD V HEATLEY MB, MRCP, medical registrar R J COLLINS, MB, MRCP, senior house officer

P D JAMES, MRCP, MRCPATH, consultant pathologist

MICHAEL ATKINSON, MD, FRCP, consultant physician purposes gastric secretory studies were also performed in 13 patients (eight men, five women; mean age 49 years) with duodenal ulcer who had not undergone operations.

The presence and degree of oesophagitis were established in all patients by endoscopic and histological examination. The severity of oesophagitis at endoscopy was graded by the same observer as being: none; mild (loss of vessel pattern with patchy or generalised mucosal hyperaemia); moderate (an inflamed mucosa with increased friability); or severe (ulceration of the mucosa with or without stricture formation, spontaneous mucosal bleeding, or both). Endoscopic mucosal biopsy specimens from the oesophageal mucosa at a fixed point $3 \mathrm{~cm}$ above the cardia were assessed histologically without knowledge of the clinical condition of the patient.

Oesophageal manometry was performed in the left lateral position using a train of three polyvinyl chloride tubes each of $1.5 \mathrm{~mm}$ diameter with side holes $5 \mathrm{~cm}$ apart, perfused at a rate of $0.5 \mathrm{ml} / \mathrm{min}$ and connected to pressure transducers and an ultraviolet-light recorder. Resting lower oesophageal sphincter pressure was measured by the rapid pull-through method ${ }^{6}$ taking the mean of nine measurements obtained at three pull-throughs. The height of the peristaltic pressure wave in the lower oesophagus in response to swallowing $20 \mathrm{ml}$ of water was measured in each patient. Satisfactory results were obtained in 24 patients.

\section{TESTS OF VAGAL FUNCTION}

Insulin and pentagastrin gastric acid secretory tests were performed on 28 patients with gastro-oesophageal reflux and 13 with duodenal ulcer according to the method described by Hosking et al. ${ }^{7}$ After a $60-$ minute basal collection of gastric secretion an intravenous injection of neutral insulin sufficient to lower blood glucose concentration to under $2.22 \mathrm{mmol} / 1(40 \mathrm{mg} / 100 \mathrm{ml})$ was given and gastric secretion collected for a further 75 minutes. Thereafter pentagastrin $(6 \mu \mathrm{g} / \mathrm{kg}$ body weight) was injected subcutaneously and gastric secretion aspirated for a further 60 minutes by constant hand suction through a tube positioned with its distal tip lying in the gastric antrum; no allowance was made for pyloric loss. Peak acid output after insulin hypoglycaemia was expressed as a percentage of that after pentagastrin, and this peak acid output ratio was used as an index of the proportion of gastric parietal cells with intact vagal innervation.

Pulse-rate variability with respiration-Electrocardiographic recordings of heart rate were made in maximum inspiration followed by maximum expiration while the patient rested in the supine position. This procedure was repeated four times on 27 patients with gastrooesophageal reflux, and the mean pulse-rate variation with respiration was calculated by measuring the R-R intervals on the electrocardiographic tracing.

\section{Results and comment}

Manometry-Lower oesophageal sphincter pressure ranged from 0 to $26 \mathrm{~mm} \mathrm{Hg}$ (mean 9.5) and the amplitude of peristaltic waves from 12 to $27.5 \mathrm{~mm} \mathrm{Hg}$ (mean 19.5) in the patients with gastro-oesophageal reflux, nine of whom showed manometric evidence of oesophageal spasm.

Insulin: pentagastrin gastric acid output-The peak acid output ratio in 13 patients with duodenal ulcer ranged from $34 \%$ to $146 \%$, which is comparable to the range of $45-165 \%$ found by Venables. Thirty-four per cent was regarded as the lower limit of the peak acid output ratio in patients with an intact vagus nerve: seven of the 28 patients with gastro-oesophageal reflux hence showed evidence of vagal impairment (fig 1 ).

Manometric findings in relation to peak acid output ratio-Those patients with a normal peak acid output ratio had a mean lower oesophageal sphincter pressure of $11.3 \mathrm{~mm} \mathrm{Hg}$ compared with 6.25 $\mathrm{mm} \mathrm{Hg}$ in those patients with a subnormal ratio. This difference was not significant. The difference in the mean amplitude of oesophageal 
peristalsis between those with normal peak acid output ratios and those with ratios below normal was not significant. The peak acid output ratios were compared with the manometric evidence of the presence or absence of oesophageal spasm (fig 2), and the 15 patients with gastro-oesophageal reflux who had no manometric evidence of spasm had significantly lower ratios (mean $49 \cdot 2$ ), than the nine with manometric evidence of spasm (mean 99.4) $(p<0.001)$. There was also a significant difference in age between these two groups, the mean age for those with spasm being 42 years and that for those without 57 years $(p<0 \cdot 02)$.

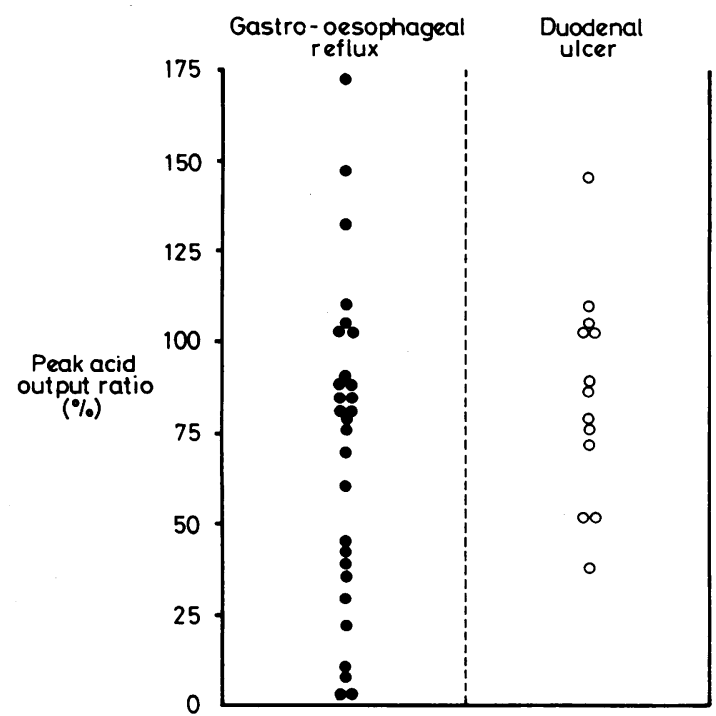

FIG 1-Peak acid output after insulin hypoglycaemia: peak acid output after pentagastrin (peak acid output ratio, \%) in 28 patients with gastro-oesophageal reflux and 13 patients with duodenal ulcer.

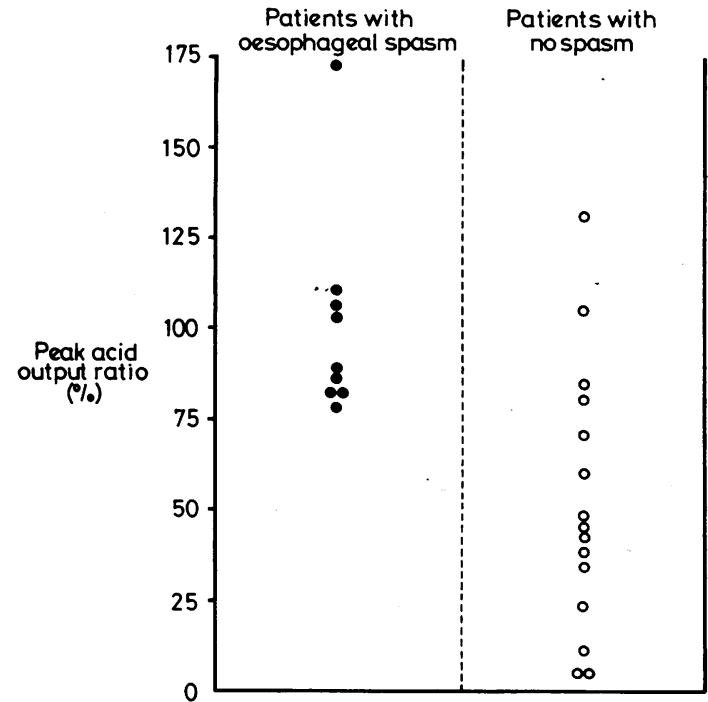

FIG 2-Peak acid output after insulin hypoglycaemia: peak acid output after pentagastrin (peak acid output ratio, \%) in relation to manometric evidence of presence or absence of oesophageal spasm.

Endoscopic and oesophageal mucosal biopsy findings in relation to peak acid output ratio-Although those patients with severe oesophagitis as assessed by endoscopy tended to have lower peak acid output ratios than the other groups (fig 3), this was not significant. The specimens obtained at biopsy were usually of squamous mucosa but were sometimes of columnar gastric mucosa, which made comparison of the severity of inflammation difficult. No relation between severity of inflammation and peak acid output ratio was apparent.

Pulse-rate variability with respiration-In health, pulse-rate variation with respiration declines with increasing age ( $T$ Bennett, un-

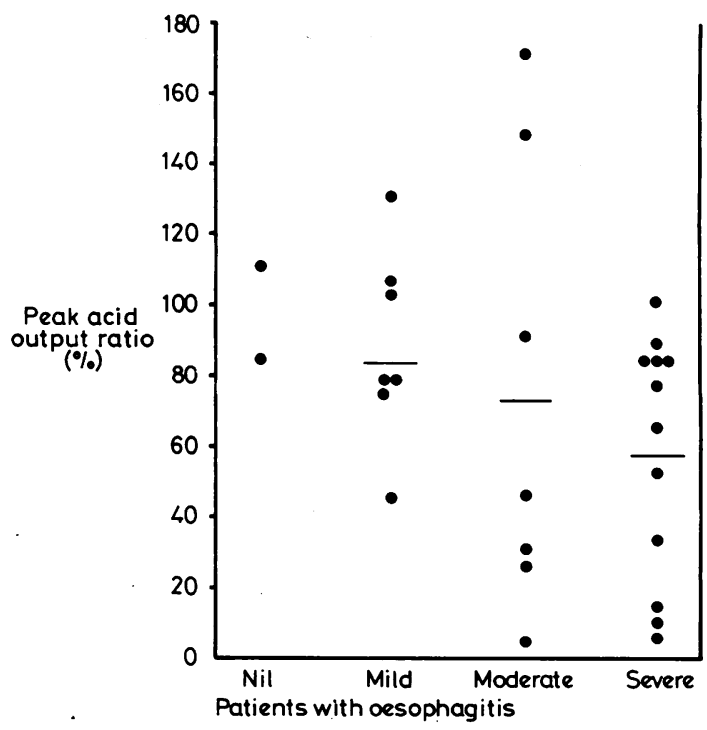

FIG 3-Peak acid output after insulin hypoglycaemia: peak acid output after pentagastrin (peak acid output ratio, \%) in relation to degree of oesophagitis as assessed by appearance at endoscopy. Bars are means.

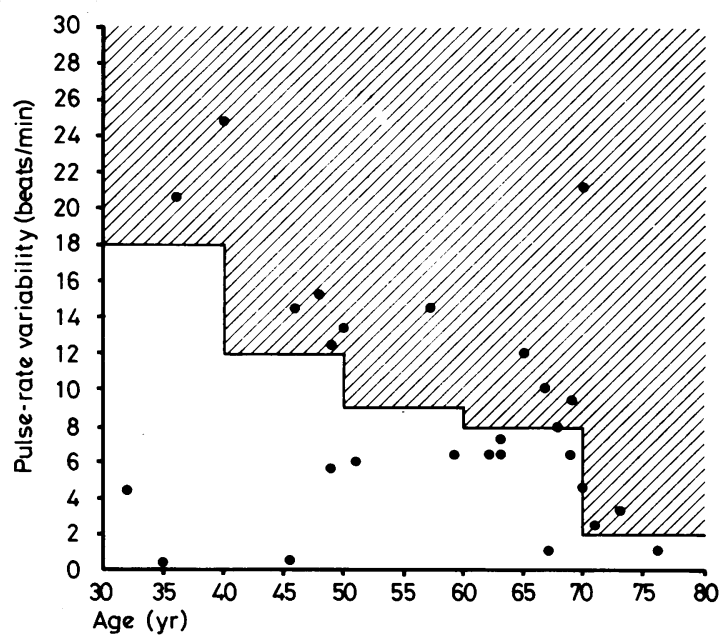

FIG 4-Mean pulse-rate variability in relation to age in 27 patients with gastro-oesophageal reflux. Shaded area shows limits of normal values.

published observations). Even when this was taken into account, however, 12 patients showed abnormally low values (fig 4). There was no correlation between abnormal values in this test and abnormal peak acid output ratios.

\section{Discussion}

The abnormalities in the peak acid output ratio that we found suggest that vagal efferent function in the upper alimentary tract is impaired in about a quarter of patients with gastrooesophageal reflux. The abnormally low pulse-rate variability found in $44 \%$ of our patients with gastro-oesophageal reflux suggests that autonomic changes are not confined to the vagal supply of the alimentary tract but that they may represent a more widespread disorder. Since we found no correlation between abnormal peak acid output ratio and abnormal heart-rate variability, the distribution and degree of vagal dysfunction probably vary from patient to patient.

Although the basal tone of the lower oesophageal sphincter is thought to be largely myogenic, it is established that sphincter contraction, particularly under stress, is regulated by neural 
influences. After surgical truncal vagotomy the rise in spinincter tone normally seen after increase in intra-abdominal pressure ${ }^{2}$ and after the ingestion of a meal ${ }^{9}$ is greatly diminished. Whether resting lower oesophageal sphincter pressure is reduced after this operation is less certain, and, although some workers have found this to be so, ${ }^{10}$ others have been unable to confirm these findings. ${ }^{2}{ }^{11}$ At surgical truncal vagotomy the nerves are probably sectioned at too low a level to deprive the lower oesophageal sphincter of its efferent nerve supply, and the effects on this sphincter are probably caused by interruption of the afferent fibres of the reflex arc. Hence, these effects are not strictly comparable with the efferent vagal deficit in patients with gastro-oesophageal reflex that our findings suggest.

Whether and how the vagal dysfunction we have found is related to gastro-oesophageal reflux remains uncertain. This dysfunction is probably not simply the effect of oesophagitis, since although the inflammation may extend into the perioesophageal tissues this would not account for the dysfunction of cardiac vagal fibres seen in some of our patients. Vagal impairment was found more often in older patients and may represent a degenerative process that causes or aggravates gastro-oesophageal reflux. One mechanism might be that the loss of vagal function favours gastric statis, and the presence of a large amount of irritant material in the stomach increases gastro-oesophageal reflux and oesophagitis. External scanning with the gammacamera has shown delayed gastric emptying of both solid and liquid meals in patients with hiatal hernia, ${ }^{4}$ although others using a double-sampling technique with phenolsulphonphthalein (phenol red) as an inert marker could not show a definite change in gastric emptying in patients with gastro-oesophageal reflux nor in those with peptic oesophageal stricture. ${ }^{12}$

Vagal impairment has been incriminated in the pathogenesis of diffuse oesophageal spasm: changes shown by electron microscopy in vagal fibres in oesophageal tissue removed at operation have been reported in patients with oesophageal spasm. ${ }^{13}$ Diffuse oesophageal spasm may result from several causes, and one of the commonest of these is gastro-oesophageal reflux. Our findings suggest that in this variety of oesophageal spasm efferent vagal function is unimpaired, although they do not exclude afferent vagal fibre damage.

Requests for reprints should be addressed to Dr Michael Atkinson, University Hospital, Nottingham NG7 2UH.

\section{References}

${ }^{1}$ Lind JF, Warrian WC, Wankling WJ. Responses of the gastro-oesophageal junction to increase in intra-abdominal pressure. Can $\mathcal{F}$ Surg 1966;9: 32-8.

2 Angorn IB, Dimopoulos G, Hegarty MM, Moshal MG. The effect of vagotomy on the lower oesophageal sphincter-a manometric study. Br f Surg 1977;64:466-9.

3 Alexander-Williams J, Cox AJ. After vagotomy. London: Butterworth, 1969.

4 Donovan IA, Harding LK, Keighley MRB, Griffin DW, Collis JL. Abnormalities of gastric emptying and pyloric reflux in uncomplicated hiatus hernia. Br $\mathcal{F}$ Surg 1977;64:847-8.

5 Stewart IM, Hosking DJ, Preston BJ, Atkinson M. Oesophageal motor changes in diabetes mellitus. Thorax $1976 ; 31: 278-83$.

${ }^{6}$ Dodds WJ, Hogan WJ, Stef JJ, Miller WN, Lyndon SB, Arndorfer RC. A rapid pull-through technique for measuring lower oesophageal sphincter pressure. Gastroenterology 1975;68:437-43.

${ }^{7}$ Hosking DJ, Moody F, Stewart IM, Atkinson M. Vagal impairment of gastric secretion in diabetic autonomic neuropathy. $\mathrm{Br} \mathrm{Med} \mathcal{F} 1975$; ii:588-91.

${ }^{8}$ Venables CW. The value of a combined pentagastrin/insulin test in studies of stomal ulceration. Br 7 Surg 1970;57:757-61.

- Csendes A, Oster M, Brandsborg O, Moeller J, Brandsborg M, Amdrup E. Gastro-esophageal sphincter pressure and serum gastrin studies following food intake before and after vagotomy for duodenal ulcer. Scand f Gastroenterol 1978;13:885-9.

10 Alexander-Williams J, Woodward DAK. The effect of sub-diaphragmatic vagotomy on the function of the gastro-oesophageal sphincter. Surg Clin North Am 1967;47:1341-4.

11 Mann CV, Hardcastle JD. The effect of vagotomy on the human gastrooesophageal sphincter. Gut 1968;9:688-95.

12 Csendes A, Henriquez A. Gastric emptying in patients with reflux esophagitis or benign strictures of the esophagus secondary to reflux compared to controls. Scand $\mathcal{F}$ Gastroenterol 1978;13:205-7.

13 Casella RR, Ellis FH, Brown AL. Diffuse spasm of the lower part of the oesophagus-fine structure of esophageal smooth muscle and nerve. fAMA $1965 ; 191: 379-82$.

(Accepted 17 December 1979)
ONE HUNDRED YEARS AGO Mrs Rhoda Hulse Bishop, the widow of a medical man, was prosecuted by the Commissioners in Lunacy, and tried and convicted at the assizes at Northampton, in January last, before $\mathrm{Mr}$ Justice Stephen, who reserved a case for the decision of the Court for Crown Cases Reserved. The offence charged was the receiving into her house two or more lunatics, such house not being duly licensed. It appeared that Mrs Bishop admitted into her house, for the purpose of medical treatment, young women who were suffering from "hysteria, nervousness, and perverseness"; and the question for the jury was, whether or not one or other of these young women was lunatic, idiot, or of unsound mind; for if so, as she had an undoubted lunatic under certificates in her house, this would constitute the reception of two or more lunatics, which is an offence. One of the Commissioners in Lunacy was called as a witness for the prosecution, and another for the defence; and it appeared from their evidence, as reported, that neither of them had been able to discover the lunacy of a particular patient, Miss B, whose lunacy was especially relied upon to ensure a conviction. Mr Justice Stephen told the jury that, "by the law of this country, people were either sane or insane, and that there was no middle class of persons in the borderland"; but, in summing up, he said that, in insanity, "there was a borderland in which there was considerable latitude for opposite opinions." The rule of law, therefore, according to this very learned and acute judge, is opposed to the truth of nature. He also told the jury that: "The best definition of a lunatic as regards this Act he could give was a person whose habitual mental state was such as to show that he was not in a fit condition to be entrusted with the control over his own actions." A lunatic is a person who needs control; and a person who needs control is a lunatic. If poor Mrs Bishop had been aware of this definition, she would scarcely have advertised for patients suffering from "hysteria, nervousness, and perverseness"; and, for the future, every person who exercises control over any other person must beware of the law; for either he exercises control over a person who is fit to control himself, which is an offence; or he exercises control over a lunatic, which is an offence also, unless all the complicated conditions of the Lunacy Acts have been complied with. But even this was not the point which brought this criminal prosecution of Mrs Bishop under the notice of the Court for Crown Cases Reserved. It was the dictum of the judge that "it was immaterial whether the defendant honestly believed the persons she received were not lunatics. It is one of the cases which the law says shall not be done; and, if it be done, it is done at the peril of the person who does it." Upon this ruling, the jury found that Miss B was insane; and, as there was a second person actually under certificates in the house, they were obliged to find the prisoner guilty; but, also, "they found that she did honestly and on reasonable grounds believe that no one of her patients was a lunatic, except, of course, the admitted lunatic."

The verdict of guilty appears to have been come to on the ruling of the judge. It was proved by a nurse that she had to give Miss $B$, and also a Miss M, a cold bath every day at eleven; "and that they sometimes objected to take their bath, and that she had to undress them, but never had to use force to put them into the bath." This, of course, is control, and therefore lunacy; and therefore Mrs Bishop had two or more lunatics in her unlicensed house; and although she did not know that they were lunatics, that was immaterial, and she was guilty, and she was bound over in the sum of $£ 100$ to come up for judgment when called upon.

The Court for Crown Cases Reserved held that it was a question for the jury; that is to say, whether Miss B was a lunatic or not, whatever might be thought by the prisoner or by the Commissioners who had seen her; and therefore the conviction has been affirmed. It would be interesting to know the amount of the little bill which the public will have to pay for this prosecution of a poor woman who did not know that she was doing wrong, and whose ignorance was shared by some of her prosecutors. (British Medical fournal, 1880.) 